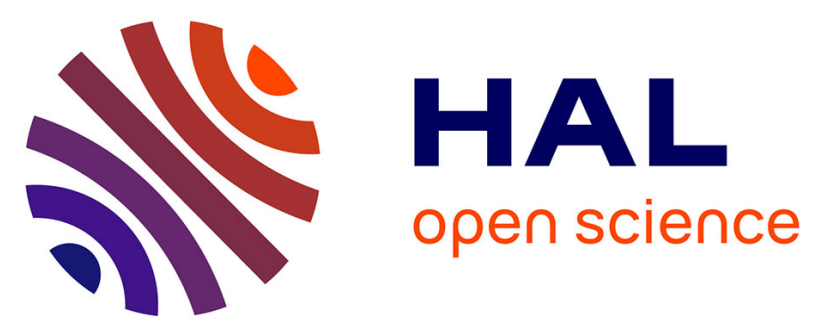

\title{
Two Expert Diagnosis Systems for SMEs: From Database- only Technologies to the Unavoidable Addition of AI Techniques
}

Sylvain Delisle, Josée St-Pierre

\section{To cite this version:}

Sylvain Delisle, Josée St-Pierre. Two Expert Diagnosis Systems for SMEs: From Database- only Technologies to the Unavoidable Addition of AI Techniques. VIIth International Conference on KnowledgeBased Intelligent Information and Engineering Systems, Sep 2003, Oxford, United Kingdom. hal01704979

\author{
HAL Id: hal-01704979 \\ https://hal.science/hal-01704979
}

Submitted on 8 Feb 2018

HAL is a multi-disciplinary open access archive for the deposit and dissemination of scientific research documents, whether they are published or not. The documents may come from teaching and research institutions in France or abroad, or from public or private research centers.
L'archive ouverte pluridisciplinaire HAL, est destinée au dépôt et à la diffusion de documents scientifiques de niveau recherche, publiés ou non, émanant des établissements d'enseignement et de recherche français ou étrangers, des laboratoires publics ou privés. 
Référence : Delisle, S. et St-Pierre, J. (2003, septembre). « Two expert diagnosis systems for SMEs: From databaseonly technologies to the unavoidable addition of AI techniques », VIIth International Conference on KnowledgeBased Intelligent Information and Engineering Systems, University of Oxford, Angleterre.

\title{
Two Expert Diagnosis Systems for SMEs: From Database- only Technologies to the Unavoidable Addition of AI Techniques
}

\author{
Sylvain Delisle ${ }^{1}$ \& Josée St-Pierre ${ }^{2}$ \\ Institut de recherche sur les PME \\ Laboratoire de recherche sur la performance des entreprises \\ Université du Québec à Trois Rivières \\ 1 : full professor, Département de mathématiques et d'informatique \\ 2 : full professor, Département des sciences de la gestion \\ C.P. 500, Trois-Rivières, Québec, Canada, G9A 5H7 \\ Phone : 1-819-376-5011+3832 \\ Fax : 1-819-376-5185 \\ Email : \{sylvain_delisle, josee_st-pierre\}@uqtr.ca \\ Web : www.uqtr.ca/ $\{\sim$ delisle, dsge $\}$
}

\begin{abstract}
In this application-oriented paper, we describe two expert diagnosis systems we have developed for SMEs. Both systems are fully implemented and operational, and both have been put to use on data from actual SMEs. Although both systems are packed with knowledge and expertise on SMEs, neither has been implemented with AI techniques. We explain why and how both systems relate to knowledge-based and expert systems. We identify aspects of both systems that will benefit from the addition of AI techniques in future developments.
\end{abstract}

\section{Expertise for Small and Medium-sized Enterprises (SMEs)}

The work we describe here takes place within the context of the Research Institute for SMEs The specific lab in which we have conducted the research projects we refer to in this paper is

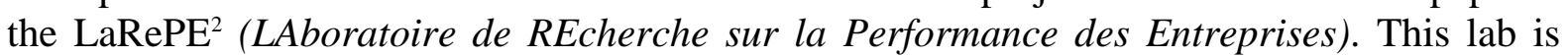
mainly concerned with the development of scientific expertise on the study and modeling of SMEs' performance, including a variety of interrelated subjects such as finance, management, information systems, production, technology, etc. The vast majority of research projects carried out at the LaRePE involves both theoretical and practical aspects, often necessitating in-field studies with SMEs. As a result, our research projects always attempt to provide practical solutions to real problems confronting SMEs.

In this application-oriented paper we briefly describe two expert diagnosis systems we have developed for SMEs. Both can be considered as decision support systems (Turban and Aronson, 2001). The first is the PDG system: a benchmarking software that evaluates production and management activities, and the results of these activities in terms of productivity, profitability, vulnerability and efficiency. The second is the eRisC system: a software that helps identify, measure and manage the main risk factors that could compromise the success of SME development projects. Both systems are fully implemented and operational. Moreover, both have been put to use on data from actual SMEs.

What is of particular interest here, especially from a knowledge-based systems perspective, is the fact that although both the PDG and the eRisC systems are packed with knowledge and

\footnotetext{
${ }^{1}$ The core mission of the Institute (http: //www.uqtr.ca/inrpme/anglais/index.html), which supports fundamental and applied research, is to foster the advancement of knowledge on SMEs to contribute to their development.

2 http: //www. uqtr.ca/inrpme/larepe/
} 
expertise on SMEs, neither has been implemented with Artificial Intelligence (AI) techniques. However, if one looks at them without paying attention to how they have been implemented, they qualify as "black-box" diagnostic expert systems. In the following sections, we provide further details on both systems and how they related to knowledge-based and expert systems. We also identify aspects of both systems that could benefit from the addition of AI techniques in future developments.

\section{The PDG System: Diagnostic of SMEs' Performance}

The PDG system evaluates a SME from an external perspective and on a comparative basis in order to produce a diagnosis of its performance and potential, complemented with relevant recommendations ${ }^{3}$. An extensive questionnaire is used to collect relevant information items on the SME to be evaluated. Data extracted from the questionnaire is computerized and fed into the PDG system. The latter performs an evaluation in approximately 3 minutes by contrasting the particular SME with an appropriate group of SMEs for which we have already collected relevant data. The PDG's output, report in Figure 1 below, is a detailed report in which 28 management practices (concerning human resources management, production systems and organization, market development activities, accounting, finance and control tools), 20 results indicators and 22 general information items are evaluated, leading to 14 recommendations on short term actions the evaluated SME could undertake to improve its overall performance.

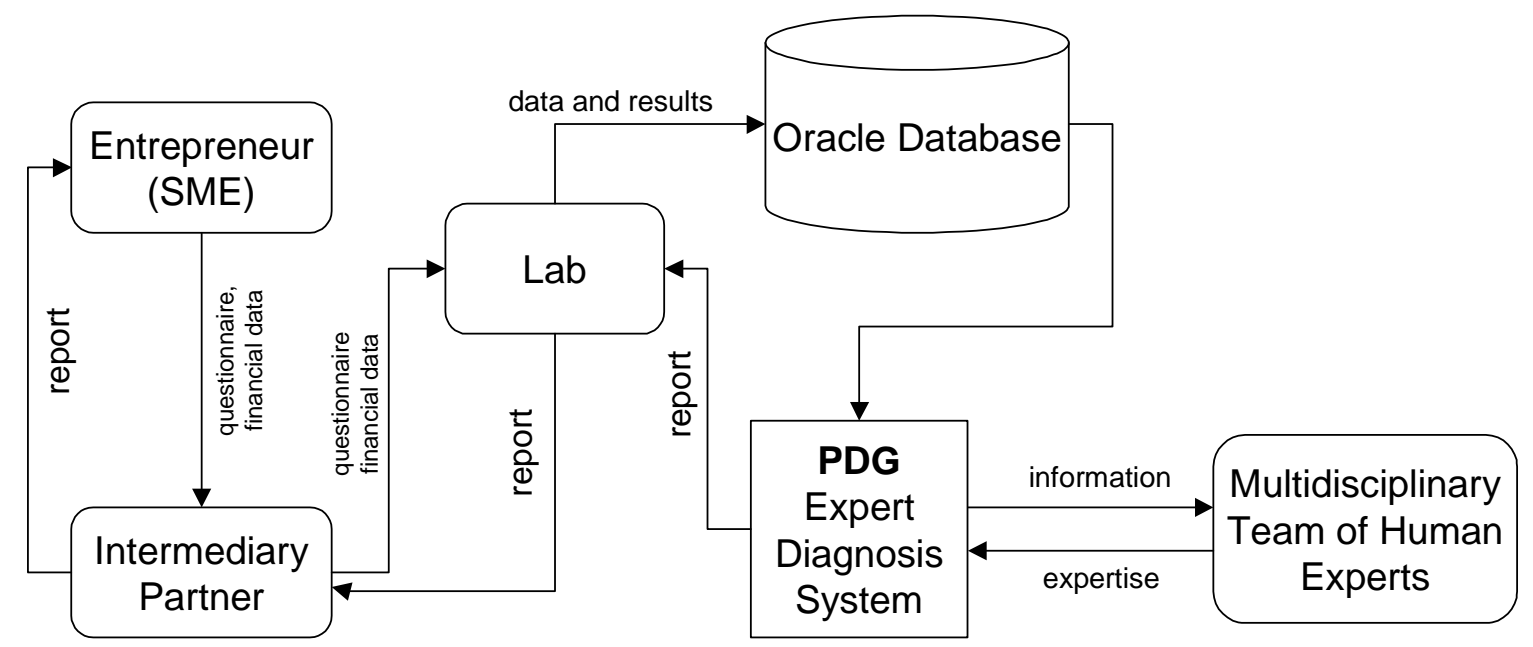

Figure 1. The PDG system ${ }^{4}$ evaluation of SMEs, from an external perspective and on a comparative basis, in order to produce a diagnosis of their performance and potential

As shown in Figure 1, the PDG expert diagnosis system is connected to an Oracle database which collects all the relevant data for benchmarking purposes - the PDG also uses the SAS statistics package, plus Microsoft Excel for various calculations and the generation of the final output report. The PDG reports are constantly monitored by a team of multidisciplinary human experts in order to ensure that recommendations are valuable for the entrepreneurs. This validation phase, which always takes place before the report is sent to the SME, is an occasion to make further improvements to the PDG system, whenever appropriate. It is also a

\footnotetext{
${ }^{3}$ Although we usually refer to the PDG system as a diagnostic system it is in fact a hybrid diagnostic-recommendation system as it not only identifies the evaluated SME's weaknesses but it also makes suggestions on how to address these weaknesses in order to improve the SME's performance.

${ }^{4}$ Further details on the insides of the PDG expert diagnosis system will be provided in the final version of the paper.
} 
valuable means for the human experts to update their own expertise on SMEs. Figure 1 also shows that an intermediary partner is part of the process in order to guarantee confidentiality: nobody in our lab knows to what companies the data are associated.

The current version of the PDG system has been in production for 2 years. So far, we have produced more than 600 reports and accumulated in the PDG's database the evaluation results of approximately 400 different manufacturing SMEs. A recent study was made of 307 Canadian manufacturing SMEs that have used the PDG report, including 49 that have done so more than once. Our results show that the PDG's expert benchmarking evaluation allows these organisations to improve their operational performance, confirming the usefulness of benchmarking but also, the value of the recommendations included in the PDG report concerning short term actions to improve management practices (St-Pierre et al., 2002).

\section{The eRisC System: Risk Assessment of SMEs' Development Projects}

SMEs often experience difficulties accessing financing to support their activities in general, and their R\&D and innovation activities in particular. Establishing the risk levels of innovation activities can be quite complex and there is no formalized tool to help financial analysts assess them and correctly implement compensation and financing terms that will satisfy both lenders and entrepreneurs. This situation creates a lot of pressure on the cash resources of innovating SMEs. Based on our team's experience with SMEs and expertise with the assessment of risk, and thanks to the contribution of several experts that constantly deal with SMEs development projects, we have developed a state-of-the-art Web-based software called $\mathrm{eRis}^{\mathrm{s}}$ (Figure 2 below).

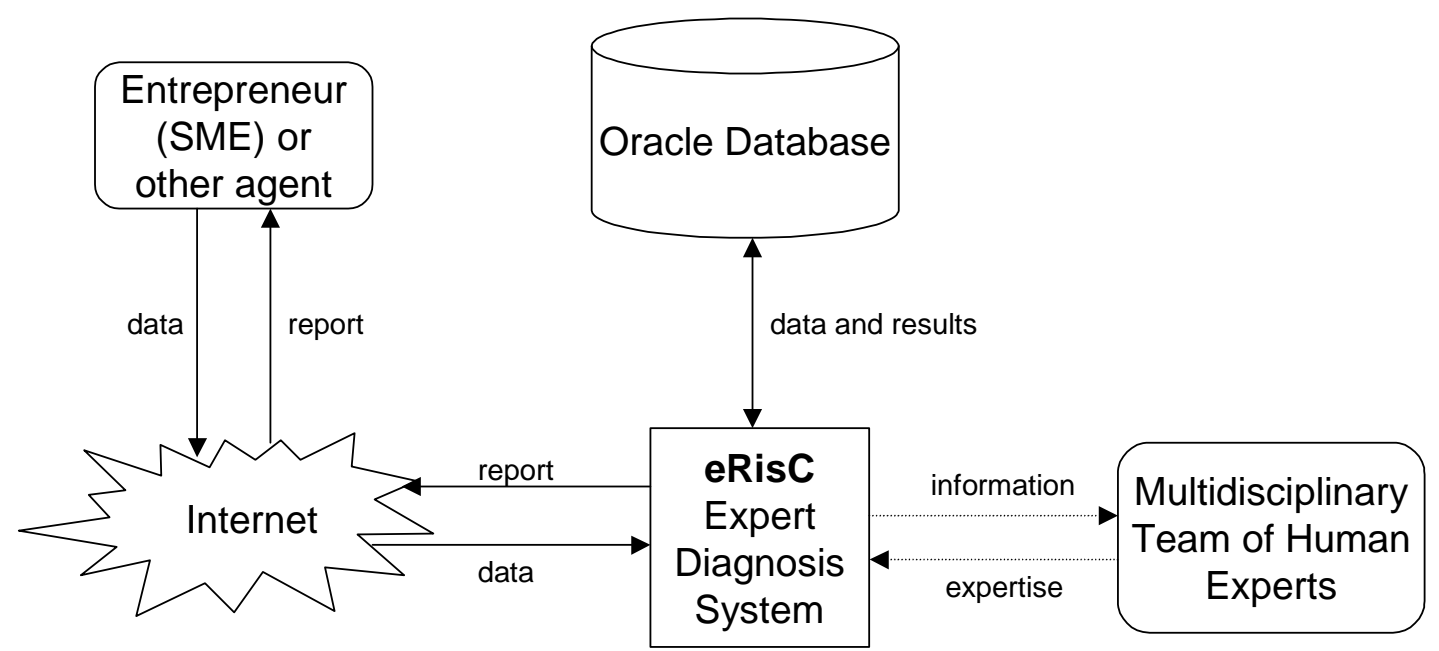

Figure 2. The eRisC system a Web-based software that helps identify, measure and manage the main risk factors involved in SME development projects

The eRisC expert diagnosis system identifies, measures and allows to manage the main risk factors that could compromise the success of SMEs development projects including expansion, export and innovation projects, each of which is the object of a separate section of the software. An extensive dynamic, Web-based questionnaire is used to collect relevant information items on the SME expansion project to be evaluated. The contents of the questionnaire are based on an extensive review of literature in which we identified over 200 risk fac-

\footnotetext{
${ }_{6}^{5}$ https://oraprdnt.uqtr.uquebec.ca/erisc/index.jsp

${ }^{6}$ Further details on the insides of the eRisC expert diagnosis system will be provided in the final version of the paper.
} 
tors acting upon the success of SMEs development projects. For example, factors associated with the export activity are export experience, commitment/planning, target market, product, distribution channel, shipping and contractual/financial aspects. These seven elements are broken down into 21 sub-elements involving between 58 and 147 questions. Data extracted from the questionnaire is fed into an elaborated knowledge-intensive algorithm that computes risk levels and identifies main risk elements associated with the evaluated project.

As shown in Figure 2, the eRisC expert diagnosis system is connected to an Oracle database which collects all the relevant data. Since eRisC was developed after the PDG system, it benefited from the most recent Web-based technologies (e.g. Oracle Java) and was right from the start designed as a fully automated system. More precisely, contrary to the PDG reports, there is no need to constantly monitor eRisC's output reports - thus the dotted arrows on the right-hand side of Figure 2 above. eRisC was developed for and validated by entrepreneurs, economic agents, lenders and investors, to identify the main risk factors of SMEs development projects in order to improve their success rates and facilitate their financing. As of now, various organizations are starting to put $\mathrm{eRisC}$ at use in real life situations, allowing us to collect precious information in eRisC's database on SMEs projects and their associated risk assessment.

\section{AI-less Intelligent Decision Support Systems}

A good deal of multi-domain expertise and informal knowledge engineering was invested into the design of the PDG and the eRisC expert diagnosis systems. In fact, at the early stage of the PDG project, which was developed before eRisC, it was even hoped that an expertsystem approach would apply naturally to the task we were facing. A prototype expert system was in fact developed for a subset of the PDG system dealing only with human resources.

However, reality turned out to be much more difficult than anticipated. In particular, the knowledge acquisition, knowledge modelling, and knowledge validation/verification phases (Fensel and Van Harmelen, 1994; Rouge et al., 1995; Matsatsinis et al., 1997; Sierra-Alonso, 2000; Caulier and Houriez, 2001) were too demanding in the context of our resources constraints especially in the context of a multidisciplinary domain such as that of SME for which little formalized knowledge exists. Indeed, many people were involved, all of them in various specialization fields (i.e. management, marketing, accounting, finance, human resources, engineering, technical, information technology, etc.) and with various backgrounds (researchers, graduate students, research professionals and, of course, entrepreneurs).

As to the eRisC system, since it was another multi-domain multi-expert project, and thanks to our prior experience with the PDG system, it was quickly decided to stay away from AIrelated approaches and techniques. Of course, this does not mean that AI tools were inappropriate for those two projects. As a research team involved in an applied project, we made a rational decision based on our experience on a smaller scale experiment (i.e. the prototype expert system on human resources), on our time and budget constraints, and on the welldocumented fact that multi-domain multi-expert knowledge acquisition and modelling constitutes a great difficulty. Yet another factor that had great influence on our design decisions was the fact that both projects started out on paper as questionnaires which led naturally to database building and all the database-related software development. As a result, both the PDG and eRisC systems ended up as knowledge-packed systems $\square$ built on database techno-

\footnotetext{
${ }^{7}$ Further details on how knowledge is represented in both systems will be provided in the final version of the paper.
} 
logy. However, as we briefly discuss in Section 5 below, we are now at a stage where we plan the addition of AI-related techniques and tools.

The current versions of the PDG and eRisC systems, although not implemented with AI techniques, e.g. knowledge base of rules and facts, inference engine, etc. (see, e.g., Santos et al. 2002; Turban and Aronson, 2001), qualifies as "black-box" expert diagnosis systems. These unique systems are based on knowledge, information and algorithms that allow them to produce outputs that only a human expert, or in fact several human experts in different domains, would be able to produce in terms of diagnosis and recommendation quality. These reports contain mostly coloured diagrams and simple explanations that are formulated in plain English (or French) so that SMEs entrepreneurs can easily understand them.

\section{New Developments: Bringing Back AI Techniques into the Picture}

The PDG and the eRisC systems are now at a stage where we can now reconsider the introduction of AI techniques in new developments. The main justification for this is the need to eliminate human intervention while preserving high quality outputs, based on rare highlyskilled knowledge and expertise. We have started to develop new modules that will increase even more the intelligence features of both systems. Here is a short, non-exhaustive list accompanied with brief explanations:

- Development of data warehouses and data mining algorithms to facilitate statistical processing of data and extend knowledge extraction capabilities. Such extracted knowledge will be useful to improve the systems' meta-knowledge level, which could be used in the systems' explanations for instance, and also to broaden human experts' domain knowledge. This phase is already in progress.

- The huge number of database attributes and statistical variables manipulated in both systems is overwhelming. A conceptual taxonomy, coupled with an elaborated data dictionary, has now become a necessary addition. For instance, the researcher should be able to find out quickly to what concepts a particular attribute (or variable) is associated, to what computations or results it is related, and so on. This phase has recently begun.

- Augment current systems with case-based reasoning and related machine learning algorithms. In several aspects of both systems, evaluation of the problem at hand could be facilitated if it were possible to establish relationships with similar problems (cases) already solved before. Determining the problems' salient features to support this approach would also offer good potential to lessen the users' burden during the initial data collection phase. This phase is part of our future plans.

\section{References}

Caulier P. and B. Houriez (2001). "L'approche mixte expérimentée (modélisation des connaissances métiers)", L'Informatique Professionnelle, 32 (195), juin-juillet, 30-37.

Fensel D. and F. Van Harmelen (1994). "A Comparison of Languages which Operationalize and Formalize KADS Models of Expertise", The Knowledge Engineering Review, 9 (2), 105-146.

Matsatsinis N.F., M. Doumpos and C. Zopounidis (1997). "Knowledge Acquisition and Representation for Expert Systems in the Field of Financial Analysis", Experts Systems with Applications, 12 (2), 247-262.

Rouge A., J.Y. Lapicque, F. Brossier and Y. Lozinguez (1995). "Validation and Verification of KADS Data and Domain Knowledge", Experts Systems with Applications, 8 (3), 333-341.

Santos J., Z. Vale and C. Ramos (2002). "On the Verification of an Expert System: Practical Issues", Lecture Notes in Artificial Intelligence \#2358, 414-424.

Sierra-Alonso A. (2000). "Definition of a General Conceptualization Method for the Expert Knowledge", Lecture Notes in Artificial Intelligence \#1793, 458-469.

St-Pierre J., L. Raymond and E. Andriambeloson (2002). "Performance Effects of the Adoption of Benchmarking and Best Practices in Manufacturing SMEs", Small Business and Enterprise Development Conference, The University of Nottingham.

Turban E. and J.E. Aronson (2001). Decision Support Systems and Intelligent Systems, Prentice Hall. 